\title{
Spatio-Temporal Patterns of Land Use and Cover Change from 1990 to 2010: A Case Study of Jiangsu Province, China
}

\author{
Ge Shi ${ }^{1,2,3,4}$ (D) Peng Ye ${ }^{1,2,3} \mathbb{D}^{-}$, Liang Ding ${ }^{5,6}$, Agustin Quinones ${ }^{4}$, Yang Li ${ }^{1,2,3}$ \\ and Nan Jiang $1,2,3, *$ \\ 1 Jiangsu Center for Collaborative Innovation in Geographical Information Resource Development and \\ Application, Nanjing Normal University, Nanjing 210023, China; 161301020@stu.njnu.edu.cn (G.S.); \\ 161301027@stu.njnu.edu.cn (P.Y.); li.yang@njnu.edu.cn (Y.L.) \\ 2 Key Laboratory of Virtual Geographic Environment, Ministry of Education, Nanjing Normal University, \\ Nanjing 210046, China \\ 3 School of Geographic Science, Nanjing Normal University, Nanjing 210046, China \\ 4 Lyles School of Civil Engineering, Purdue University, 550 Stadium Mall, West Lafayette, IN 47907, USA; \\ quinona@purdue.edu \\ 5 College of Computer and Information, Hohai University, Nanjing 210098, China; 170207040003@hhu.edu.cn \\ 6 Information Center of Jiangsu Natural Resources Department, Nanjing 210017, China \\ * Correspondence: njiang@njnu.edu.cn; Tel.:+86-025-8589-1902
}

Received: 20 January 2019; Accepted: 11 March 2019; Published: 13 March 2019

\begin{abstract}
Land use and cover change (LUCC) is one of the most significant parts of global environmental changes, which reflects the interaction between human society and natural resources. In China, the urbanization process is experiencing a rapid sprawl since the reform and open program in 1978, and there has been a serious change in situation in the human-land relationship. In this paper, taking Jiangsu province located in the eastern coastal developed region as an example, the historic evolution process of the land use situation from 1990 to 2010 was explored. Landsat images from three periods were analyzed, using the land use transition matrix model, the land use dynamic degree model, and the land use degree model to evaluate the LUCC of Jiangsu during two research periods from 1990 to 2000 and from 2000 to 2010. Additionally, logistic regression models and some quantitative analysis were applied to identify the major potential driving factors behind the LUCC during the research period based on different dimensions. The results showed the following: (1) the most obvious change was the continuous increase of built-up area and the decrease of arable land, which reflected the deterioration of the ecological environment and the accelerate of the urbanization trend. (2) The land use change dynamic degree from 2000 to 2010 was much greater than that from 1990 to 2000. (3) Socio-economic elements and human activities were the major driving forces of LUCC in Jiangsu province. Amongst these forces, the driving factors of the population change, GDP, per capita household income, and per capita housing area have an obvious effect on the arable land loss and the built-up area expansion.
\end{abstract}

Keywords: urbanization; land use and cover change; Markov; logistic regression model; driving forces; Jiangsu province

\section{Introduction}

Land use and cover change (LUCC) is one of the most significant parts of global environmental change, which is a reflection of the interaction between human society and natural resources [1-3]. Global environmental change is closely related to humanity, thus numerous topics have been put 
forward to investigate the human-land interactions, such as climatic issues, population burning, energy shortage, natural resource shortage, etc. [4-7]. Since 1992, the importance of LUCC for long-term sustainable planning has been recognized globally, when LUCC research was identified as the key project on the agenda for the 21st century as released by the United Nations. This has attracted significant attention from scholars and experts in related fields and numerous studies have already been reported around the world $[5,8,9]$. According to the World Bank Report, one of the most important reasons for land use change is the increasing demand for built-up area for urban expansion [10]. In high-speed developing countries, it is crucial to better manage land use planning as an imbalance between land and humanity may result in countless side effects. Thus, the evolution process of LUCC and its driving forces should be carefully studied [11,12].

Meanwhile, China has experienced a significant economic development period since the reform and open program in 1978, especially the eastern-developed regions like the Yangtze River Delta region. LUCC has also experienced a correspondingly huge conversion since then and in different regions across China [13]. The most obvious change is the expansion of the built-up area as part of the process of rapid urbanization, as well as the degradation of arable land and grasslands in the northern region and southern coastal regions, and water area loss and deforestation in the southern region $[14,15]$. Scholars in different fields have studied LUCC from the perspective of ecology, historical evolution, human geography, real estate, economy, etc. [16-19]. Some results have shown that the urban sprawl is occurring all over the world, not only in China, but they have also raised serious concerns including the human-land issues $[20,21]$. While China's urbanization process is experiencing an expansion, a well-organized land use plan is crucial for future sustainable development. It is necessary to learn more about the change process of LUCC and the socio-economic driving forces in order to better manage the nationwide land use planning process [22-24].

There are numerous studies on land use and cover change in different regions across the world, focusing mainly on the land use change situation during certain period, the driving forces of LUCC, the forward result of LUCC, the planning adaption for better city management, etc. [3,25]. The above-mentioned research topics have been explored on a macro scale to learn the process and evolution of land use development. From a microscale perspective, some statistical models have been applied to forecast future trends [1,26-28]. Lambin used Landsat images to discover the changes of LUCC between different time periods, as well as analyzing the cause [1]. Liu, Mooney, Foley, Moran, Turner, and some other related scholars have investigated the change process of LUCC globally from rural to urban areas $[8,11,15,29,30]$. Lambin, Le, Ralha, et al. applied various micro models like the multi-agent system model and Conversion of Land Use and its Effects (CLUE) model to simulate the future development of LUCC [31-33]. Li and Cheng analyzed the current LUCC situation and the development trends in less developed regions in western China [34,35]. Zhang, Yu, Liu, and Du applied numerous statistical models to discover the land use patterns and the driving forces of changes between different regions [10,36-38]. The existing research on the driving forces of land use changes mainly describes the spatial and temporal patterns of the current land use situation, and then, it uses statistical models to quantify the driving forces for a certain region.

To summarize, the existing studies have used numerous statistical models to describe the evolution process of land use, and to simulate its future development trend globally. However, there is a gap in the research on LUCC and its driving forces, especially on socio-economic aspects in places experiencing rapid development. In this paper, LUCC in Jiangsu province was explored, and the evolution of land use changes were quantified for the past 20 years from a macro perspective. With the technical support of remote sensing and GIS technology, this paper analyzed the land use patterns and evolution characteristics using statistical models, which provided a deep understanding of land use, and enabled the conclusion of the corresponding driving forces behind changes in various types of urban data like internet point of interest data and statistical bureau data. The objective of this study was to investigate the spatio-temporal characteristics and potential driving forces of LUCC during the rapid urbanization period in Jiangsu province, based on Landsat image data, statistical data, and internet 
point of interest data. To ensure sustainable regional development, the study results aimed to provide constructive references and useful guidance for the Planning Department to optimize comprehensive urban planning. The results and conclusions from this LUCC study can also be used to study similar regions that are also experiencing rapid economic development.

\section{Materials and Methods}

\subsection{Study Area}

Covering an area of $10.72 \times 10^{4} \mathrm{~km}^{2}$, Jiangsu province is located in the eastern coast region of China at the Yangtze River Delta urban agglomeration, spanning a longitude from $116^{\circ} 18^{\prime} \mathrm{E}$ to $121^{\circ} 57^{\prime} \mathrm{E}$ and latitude from $30^{\circ} 45^{\prime} \mathrm{E}$ to $35^{\circ} 20^{\prime} \mathrm{E}$ (see Figure 1), with the Yellow Sea on the east side, the Anhui province and the Shandong province on the northwest side, and Zhejiang province and Shanghai on the southeast side. Jiangsu province is one of the most developed regions with one of the highest population densities in China, but with only $1.1 \%$ of the total land area in Mainland China, and accounting for $10.4 \%$ of the total GDP, ranking second amongst all provinces in 2017 [39]. The permanent population of Jiangsu province has increased from 67,669 thousand to $78,693.4$ thousand, of which the urban population increased from approximately $21.6 \%$ to $60.6 \%$ of the total during the years from 1990 to 2010 [40]. The regional GDP increased from 141.6 billion Chinese Yuan (CNY) to 4142.55 billion CNY during the same research period, reflecting a rapid economic expansion of nearly 30 times. Within this period, the land use situation has experienced a great change related to the rapid urbanization process. For instance, the built-up land expanded from $12,280.82 \mathrm{~km}^{2}$ to $20,064.89 \mathrm{~km}^{2}$ [41]. There exists an increasing conflict between the land use ecology and the human societal development, which has already resulted in a series of problems like environmental pollution, land degradation, biodiversity loss, etc. [42,43].

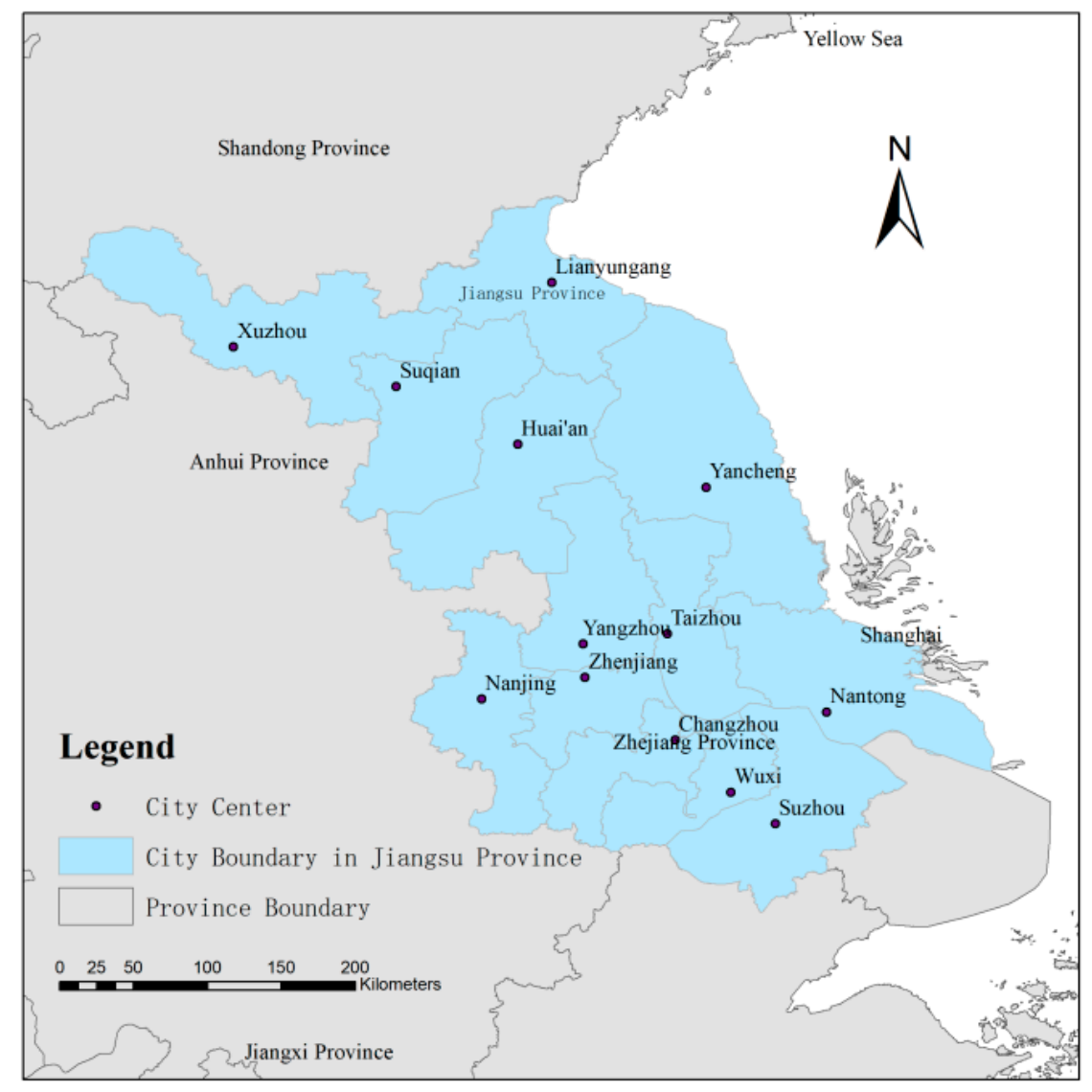

Figure 1. The geographical location of Jiangsu Province. 
The area of study consists of thirteen prefecture cities, which are Nanjing (the capital city), Wuxi, Changzhou, Suzhou, Zhenjiang, Nantong, Yangzhou, Taizhou, Xuzhou, Lianyungang, Huai'an, Yancheng, and Suqian. The whole province is divided into three parts based on the urbanization level and development period: Southern Jiangsu, including Nanjing, Suzhou, Wuxi, Changzhou, and Zhenjiang; Central Jiangsu, including Yangzhou, Nantong, and Taizhou; and Northern Jiangsu, including Huai'an, Xuzhou, Lianyungang, Yancheng, and Suqian [44]. Jiangsu is of an eastern-Asian monsoon climate. The annual temperature is approximately between $13.6^{\circ} \mathrm{C}$ to $16.1^{\circ} \mathrm{C}$ with efficient rainfall of nearly $1000 \mathrm{~mm}$ annually. Owing to mild climate, Jiangsu is called the land of fish and rice, and is one of the most important grain foundations of China [41].

\subsection{Research Data}

\section{- Land Use Data}

The land use data used in this paper were initially derived from the historical Landsat thematic mapper satellite imagery, provided by the Yangtze River Delta Science Data Center, National Science and Technology Infrastructure of China, and National Earth System Science Data Sharing Infrastructure (http://nnu.geodata.cn:8008) as in Reference [45]. The available cloud-free Landsat images used were from 1990, 1995, 2000, 2005, and 2010, with an accuracy higher than $94.3 \%$, which was suitable for the large-scale spatial analysis with the precision of a 1:100,000 scale geography map. In this paper, we chose three time phases from 1990, 2000, and 2010 to study the land use evolution trend during this twenty-year period with a rapid urbanization trend.

- Basic Data on the City

This paper used basic urban data for Jiangsu province provided by the Yangtze River Delta Science Data Center, National Science and Technology Infrastructure of China, and National Earth System Science Data Sharing Infrastructure (http://nnu.geodata.cn:8008) [45]. This dataset included the administrative region boundary, capital city, urban center, road network, and location of transportation stations. The data was stored in a shape file format.

- Socio-Economic Data

The socio-economic data used in this paper was derived from the Statistics Bureau of Jiangsu Province (http:/ / tj.jiangsu.gov.cn/col/col4009/index.html). The dataset provided the information on the socio-economic related issues of 13 cities in Jiangsu province, including the yearly population, urban and rural population, GDP of three industries, employment, retail, people's living conditions, government finance, resources and environment, energy, investment in fixed assets, agriculture, industry, construction, etc. [39-41,46]. The data was stored in an Excel file format.

\section{- Point of Interest Data}

The point of interest data of Jiangsu province was derived from the Baidu map through the web application programming interface (API) provided by the Baidu Company. The data collection and cleaning were done by the Yangtze River Delta Science Data Center [45]. This dataset provided the location information of equipment in the research region, for example the name, longitude, latitude, administrative district, etc. The POI data was divided into six categories and 21 subtypes: the six categories were the residential point, public management and public service function point, commercial service point, industry point, transportation and road point, green area and square point. The data was stored in an Excel file format. 


\subsection{Method}

\subsubsection{Land Use Types Classification}

The original dataset had six categories of land use types, which were arable land, forestry land, grassland, water area, urban and rural built-up land, and unused land. The six categories were further divided into 31 subtypes. For example, the arable land was further divided into dry land and paddy field; the forestry land was further divided into closed forestry land, open forestry land, shrub forestry land, and other types of forestry land. Based on the land use planning of Jiangsu province, considering the land use purpose and management characteristics, we distinguished the main categories of different land use types and determined the similarities. Jiangsu province has a long costal line of over 1000 kilometers, thus the intertidal zone is an important resource for land use storage. We separated the intertidal area out of the water area when doing the analysis (see Table 1).

Table 1. The classification system of land use types of Jiangsu province.

\begin{tabular}{|c|c|c|}
\hline Code & Name & Explanation \\
\hline 1 & Arable Land & $\begin{array}{l}\text { Land for growing the crops, including the dry land, paddy field, and the } \\
\text { intertidal area covered with planted crops more than three years }\end{array}$ \\
\hline 2 & Forestry & $\begin{array}{l}\text { Land for planting trees, including closed forestry land, open forestry land, } \\
\text { shrub forestry land, and other types of forestry }\end{array}$ \\
\hline 3 & Grassland & Land growing grasses, sedge, and shrubs covering more than $5 \%$ of total area \\
\hline 4 & Water Area & $\begin{array}{l}\text { Natural area covered with water or the place with water conservancy } \\
\text { facilities }\end{array}$ \\
\hline 5 & Intertidal Area & Land exposed to water that has not been used for many years \\
\hline 6 & Built-up Area & $\begin{array}{l}\text { Urban and rural built up area, including residential area, transportation area, } \\
\text { public building area, industry area, commercial area, etc. }\end{array}$ \\
\hline 7 & Other Unused Area & Other kinds of land that have not been used for years \\
\hline
\end{tabular}

Based on the classification system above, we generated LUCC situation maps for Jiangsu province over the research period in 1990, 2000, and 2010 (see Figure 2), using the ArcGIS software (ESRI, Redlands, CA, USA) and Python 3.0 (Python Software Foundation, Beaverton, OR, USA). Then, we were able to perform further analyses to calculate the land use degree and land use change dynamic degree of Jiangsu province, and to conclude the driving forces of LUCC and generate relevant thematic maps.

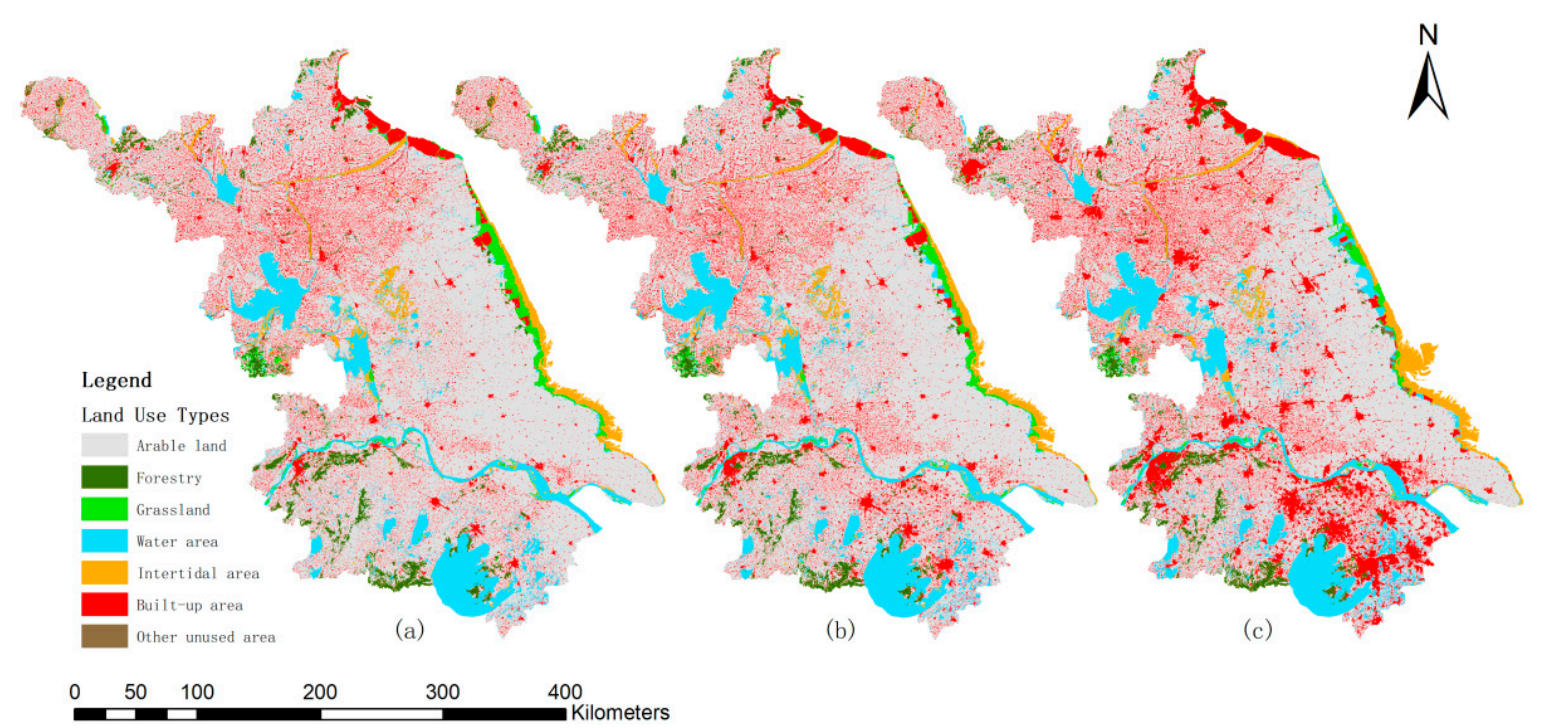

Figure 2. Land use classified map of Jiangsu province from 1990 to 2010: (a) Land use situation in 1990; (b) Land use situation in 2000; (c) Land use situation in 2010. 


\subsubsection{Markov Transition Matrix Model}

The Markov transition matrix model is used to describe the change in situation of each land use type between study periods $[47,48]$. We generated the transition matrix of Jiangsu's land use from 1990 to 2000 and from 2000 to 2010 to analyze the past changing situations, and also for the simulation of future trends. The calculation formula for the Markov transition matrix model is as follows:

$$
S_{i j}=\left[\begin{array}{ccc}
S_{11} & \cdots & S_{1 n} \\
\vdots & \ddots & \vdots \\
S_{m 1} & \cdots & S_{m n}
\end{array}\right]
$$

where $S$ is the area of each type of land use; $i$ and $j$ are the land use types before and after the research period during the transition; $i, j, m$, and $n$ in this paper represented the land use type code, and were equal to $1,2,3, \ldots, 7$ as we only had seven types of land use in Jiangsu's land use classification system. Based on the above calculation, we generated two transition matrixes, and calculated the reduced and increased amount of each land use type.

\subsubsection{Land Use Dynamic Degree Model and Land Use Degree Model}

To further study the dynamic of land use change situation, we applied the land use dynamic degree model to quantify the dynamics $[49,50]$. This model described the annual change rate of each type of land use change. The formula is as follows:

$$
S=\left\{\sum_{i j}^{n}\left(\frac{d S_{i-j}}{S_{i}}\right)\right\} \times(1 / t) \times 100 \%
$$

where $S$ is the land use dynamic degree during the research time $t ; S_{i}$ is the total area of land use type $i$ in the whole research area; $d S_{i-j}$ is the total area of land transited from type $i$ to type $j$ during the research time period $t$.

The land use degree is a description of the impact on the environment made by mankind. The natural land is used at different degrees by people in various use types and it is affected by human activity at different degrees, for example, the arable land, built-up land, etc. The unused natural land has a very low effect from mankind while artificial non-reclaimed land has the highest effect. The land use degree model expresses the comprehensive usage situation of land in a certain area and it helps to forecast future usage and changes. To quantify the land use degree, in the Database of Natural Resource of China (DNRC), Liu separated the land use types into four categories (see Table 2) based on the ecology perspective and the effect degree by humans, and gave each type a certain index to further describe the land use degree in a certain research region $[37,51-53]$. The land use degree model formula is as follows:

$$
\Delta I_{b-a}=I_{b}-I_{a}=\left\{\left(\sum_{i=1}^{n} A_{i} \times C_{i b}\right)-\left(\sum_{i=1}^{n} A_{i} \times C_{i a}\right)\right\} \times 100
$$

where $\Delta I_{b-a}$ is the change of land use degree from the research time year $a$ to year $b ; I_{a}$ and $I_{b}$ are the land use degree in the research year a and year $\mathrm{b} ; A_{i}$ is the land use degree index for land use type $i$, detailed as shown in Table 2; $C_{i a}$ and $C_{i b}$ are the percentage of the area of land use type $i$ at the time $a$ and $b$, respectively. 
Table 2. Classification and index of land use types.

\begin{tabular}{ccccc}
\hline Classification Type & Natural Unused & Natural Reclaimed & $\begin{array}{c}\text { Artificial } \\
\text { Reclaimed }\end{array}$ & $\begin{array}{c}\text { Artificial } \\
\text { Non-Reclaimed }\end{array}$ \\
\hline $\begin{array}{c}\text { Land use type } \\
\text { Index of land } \\
\text { use categories }\end{array}$ & Other unused area & $\begin{array}{c}\text { Forest, grassland, water area, } \\
\text { and intertidal area }\end{array}$ & Arable land & Built-up area \\
\hline
\end{tabular}

\subsubsection{Logistic Regression Analysis}

The logistic regression model is one of the most popular models to investigate the urban expansion pattern in environmental modeling. The statistical driving factors analysis was first carried out with the support of SPSS Version.23 software (IBM, New York, NY, USA). We built the binary logistic regression model to identify the relationship between multiple variables of driving forces factors and the LUCC [54,55].

Natural environment, land use management, and socioeconomic human activity have been recognized as the main driving factors of LUCC by the International Geosphere and Biosphere Project (IGBP) and the International Human Dimensions Program (IHDP) $[1,5,56]$. This comprises, the natural environment which includes the temperature, topography, etc.; the land use management which presents the local government policies, such as comprehensive urban planning and zoning code; and the socioeconomic human activity which includes the population change, education level, social economic structure, economic development, and so on. In theory, for the purpose of learning about the driving factors, all the components should be programmed. However, considering the local situation of Jiangsu province and the data availability, the major driving forces were identified. In this study, the major factors were grouped into three subsystems: (1) Natural environment factors, including the elevation, slope, and distance to the water area, which may affect the efficiency of arable land, intertidal area conversion, and the selection of the urban area. (2) Land use management factors, including the distance to highway, distance to urban road, distance to urban center, the density of urban commercial service facility, the density of the transportation facilities, and density of other service facilities (Figure A1). (3) Socioeconomic human activity factors, including the gross domestic product (GDP), population change, per capita household income, and per capita housing area. Social economic development may require more urban area to pursue development, while human activity may change the function of land in the corresponding area. The values of the above factors were obtained from the land use information, planning maps, Jiangsu Statistics Yearbooks, and POI data.

For the purpose of examining the relationships between LUCC and the above driving factors, the logistic regression model was applied. A set of potential driving factors were identified from the understanding of LUCC determinants. The simulated driving factors with an insignificant contribution to the LUCC were eliminated and the significant factors were retained during the model testing process. The logistic regression equations were expressed as follows:

$$
\begin{gathered}
P_{\left(y=\frac{m}{x}\right)}=\frac{\exp \left(\beta_{0 m}+\beta_{1 m} x_{1}+\beta_{2 m} x_{2}+\ldots+\beta_{k m} x_{k}\right)}{1+\sum_{i=2}^{e} \exp \left(\beta_{0 i}+\beta_{1 i} x_{1}+\beta_{2 i} x_{2} \ldots+\beta_{k i} x_{k}\right)} \\
\ln \frac{p\left(y=\frac{m}{x}\right)}{p\left(y=\frac{1}{x}\right)}=\beta_{0 m}+\beta_{1 m} x_{1}+\beta_{2 m} x_{2}+\ldots+\beta_{k m} x_{k}
\end{gathered}
$$

where $p$ is the occurrence probability of a certain land use type change; $y$ is the reference variable; $x$ is the potential driving factors; $p(y=1)$ refers to the probability that the land use type remains unchanged; $p(y=m / x)$ is the probability that the land use type changes into type $m ; \frac{p\left(y=\frac{m}{x}\right)}{p\left(y=\frac{1}{x}\right)}$ is the odds ratio of a group of events; $\beta_{0}$ is the constant; $\beta_{n}$ is the coefficient of the $n$th driving factor.

The odds ratio was calculated to express the constant effect of a predictor. The Wald value test was used in this model to explain whether this variable had a correlation with the LUCC. Non-parametric 
receiver operating characteristic (ROC) curve tests were applied to confirm the correlation model adjustment. A null value meant that this statistical test had a $p$ value lower than 0.05 .

\section{Results}

\subsection{Spatial and Temporal Patterns of Land Use and Cover Change}

Spatial superposition of land use data was used to study the spatial and temporal characteristics of LUCC in Jiangsu province over the past twenty years. With the support of the Arc/Info Grid software module (ESRI, Redlands, CA, USA), we compared each two sections of land use change situations and generated the spatial characteristic maps from 1990 to 2010 (see Figure 3). The most significant land use change was caused by the urbanization development. It was clear that the southern Jiangsu region developed first and then came the central and northern Jiangsu regions. From 1990 to 2000, the changes of land use types were mainly distributed in the southern Jiangsu region, as the southern region had a higher urbanization level at that time. The intertidal area along the eastern costal region expanded as a result of the deposits of sediment at the Yellow Sea. From 2000 to 2010, there were more obvious changes all across the province's regions compared to that of 1990 to 2000, while the southern region had a slightly higher density than the central and northern Jiangsu regions. The main changes in this period were the continuous expansion of urban built-up land and the greater reduction in arable land. The eastern costal region had even more obvious changes than before, as some of the intertidal area changed into arable land or forestry land and the sea continuously deposited sediments.
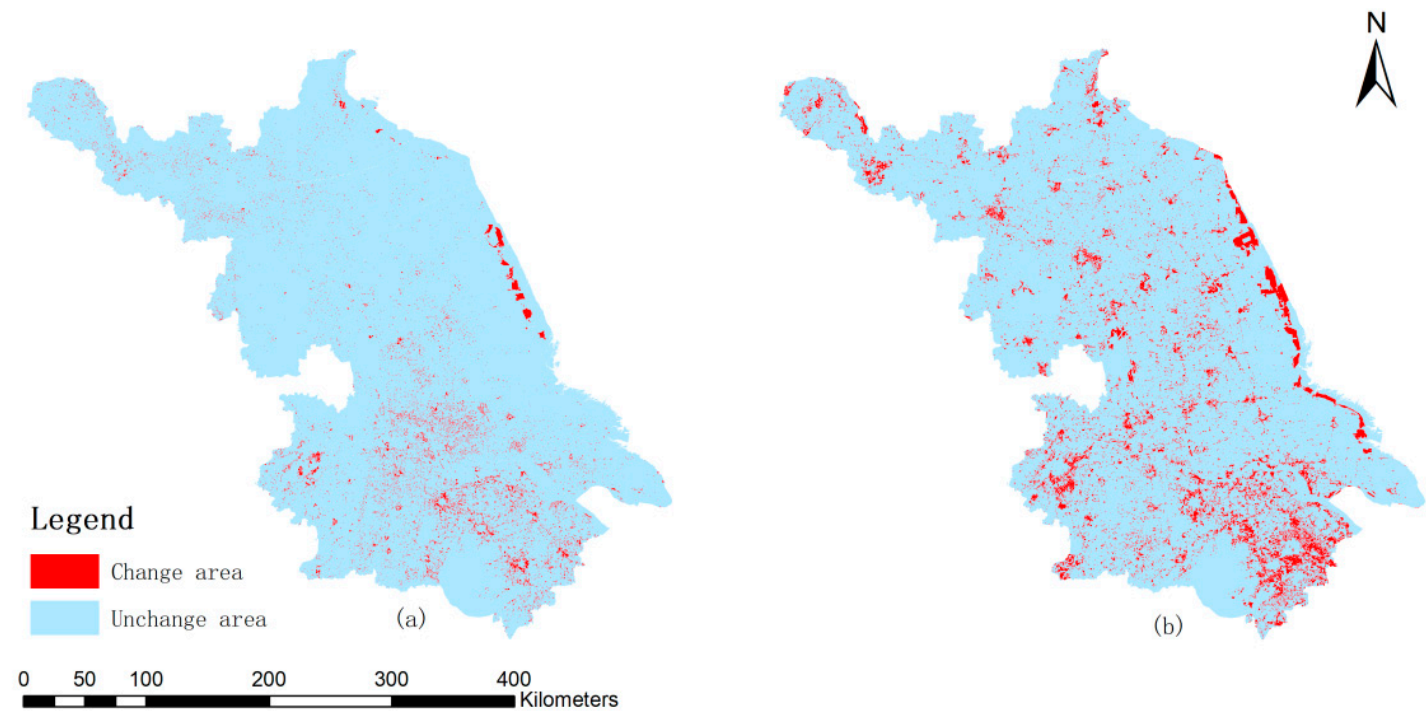

Figure 3. Distribution map of change situation of land use type of Jiangsu province from 1990 to 2010: (a) Land use type change situation from 1990 to 2000; (b) Land use type change situation from 2000 to 2010 .

With a further analysis of the amount of each type of land use, we generated a statistical amount changes map for the study period (see Figure 4). It was clear to see that the total amount of arable, forestry land, grassland, and intertidal area was continuously decreasing, while the water area and built-up area had an increasing trend from 1990 to 2010. To be specific, from 1990 to 2000, the reduction of arable land and grassland was nearly equal to the increase of built-up area and water area, while the changes of forestry, intertidal area, and other unused areas were much less. From 2000 to 2010, there was a greater amount in the reduction of arable land, forestry, grassland, and intertidal area, as well as a greater amount of the increase of water area and built-up area. 


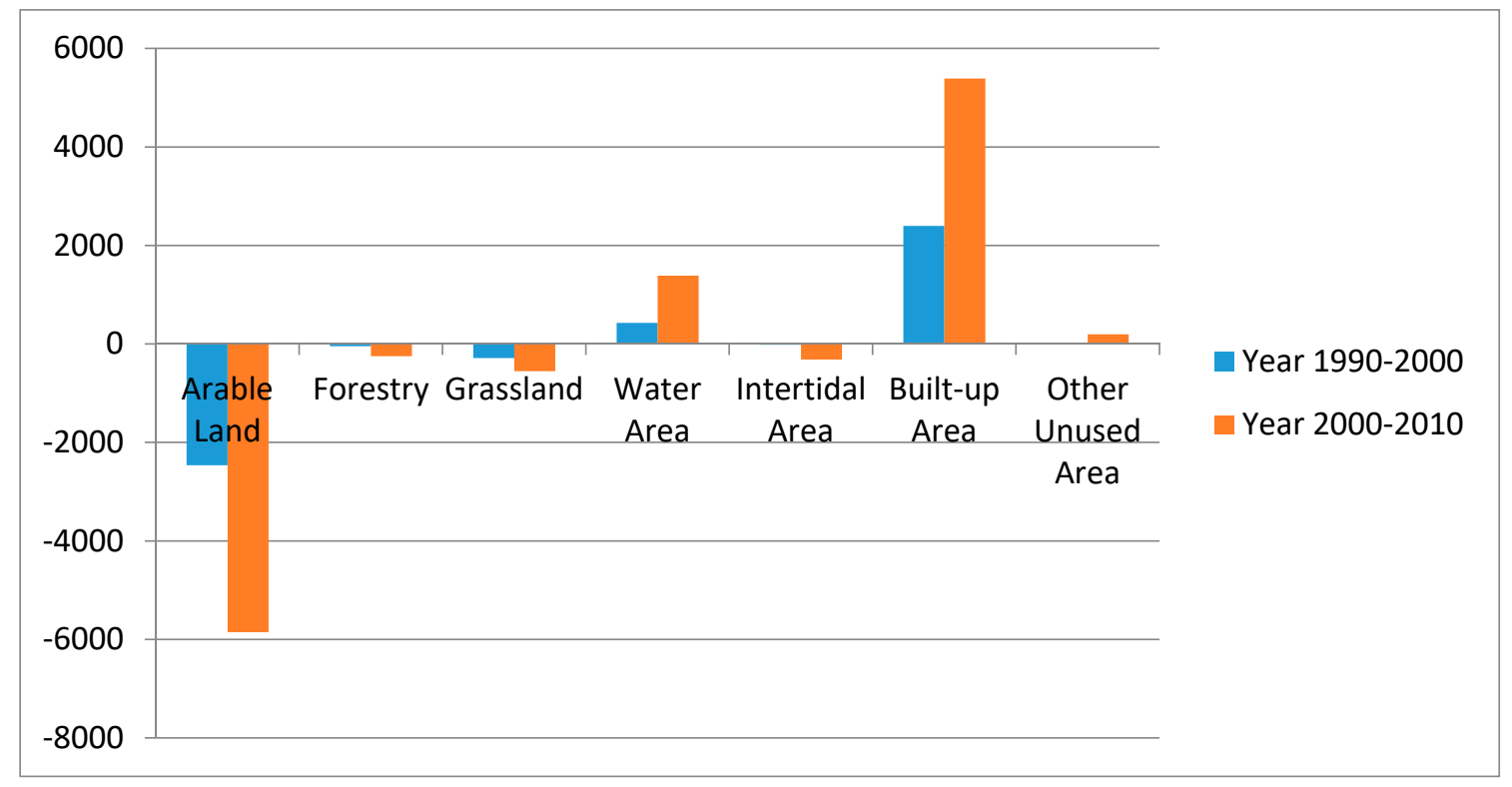

Figure 4. Statistical amount changes of land use in Jiangsu province (unit: $\mathrm{km}^{2}$ ).

From the attribute calculation of each land use type, we conducted a further comparison of LUCC during the two research phases. The most obvious change was the recession of arable land, where it covered $69.88 \%$ of the total area at an amount of $72,296.03 \mathrm{~km}^{2}$ in 1990 , but was reduced to $67.49 \%$ by a reduction amount of $2461.84 \mathrm{~km}^{2}$ in 2000 , and it continued to decline to $61.83 \%$ by an area of $5850.57 \mathrm{~km}^{2}$ to a new total area of $63,983.93 \mathrm{~km}^{2}$. Conversely, the second significant change was the increase in the built-up area, wherein it covered $11.87 \%$ of the total area at an amount of $12,280.82$ $\mathrm{km}^{2}$ in Jiangsu province in 1990, which changed to $14.18 \%$ through an increase of $2394.39 \mathrm{~km}^{2}$ in 2000 , and then continuously increased to $19.39 \%$ by an area of $5389.68 \mathrm{~km}^{2}$ in 2010 to a new total area of $20,064.89 \mathrm{~km}^{2}$.

The above mentioned data gave us a clear insight into the main characteristics of land use and cover change in Jiangsu province from 1990 to 2010. There was an obvious increase in the built-up area as Jiangsu province was experiencing a rapid urbanization period. There was an overall decrease in arable land which was taken over for urban expansion, though the arable area still accounted for the major land use type as Jiangsu province is a big agricultural province. The water area and other unused area increased significantly, while the forestry, grassland, and intertidal area decreased rapidly mainly caused by natural or other causes.

\subsection{Land Use Transition Matrix from 1990 to 2010}

We used the Markov transition matrix model to calculate the land use situation transition matrix in order to analyze the change direction of each type of land use. We employed the tabulate command of the ArcGIS software to calculate the transition matrix of LUCC in Jiangsu from 1990 to 2000 and then from 2000 to 2010 (See Tables 3 and 4). Over 20 years, there was a steady reduction of arable land changing into other types of land use, while the most significant change type was the transition into built-up area. From 1990 to 2000, the recession amount of arable land was $2621.59 \mathrm{~km}^{2}$, out of which $86.92 \%$ changed into the built-up area. From 2000 to 2010, the recession amount of arable land was $6491.61 \mathrm{~km}^{2}$, out of which $78.19 \%$ changed into the built-up area. It showed that the major transition pattern of Jiangsu province during 1990 and 2010 was the transition between the arable land and built-up area due to the urban expansion and industrial development. Owing to the environmental protection policy of returning arable land back to the natural use, there was also some arable land changed into the water, intertidal, forestry, and grassland areas, as well as conversions into arable land. To be specific, from 1990 to 2000, 13.08\% of the total changed arable land was changed into 
forestry, grassland, water, and intertidal areas, out of which the water area accounted for the largest share with $332.11 \mathrm{~km}^{2}$. From 2000 to 2010, this trend continued with $15.89 \%$ of total transition arable land changing into forestry, grassland, water, and intertidal areas, where water also accounted for the largest share with even more area of $885.36 \mathrm{~km}^{2}$. The intertidal and water areas transitioned into each other at different locations. Moreover, there was obvious grassland that changed into water areas at an area of $101.6 \mathrm{~km}^{2}$ from 1990 to 2000, and then $283.64 \mathrm{~km}^{2}$ from 2000 to 2010. Moreover, there was some grassland that changed into intertidal area from 2000 to 2010 at an area of $79.02 \mathrm{~km}^{2}$. The above water ecology region transition was mainly caused by construction of ecology parks and natural preservation parks along the eastern seaboard region.

Table 3. Land use situation transition matrix in Jiangsu province from 1990 to $2000\left(\mathrm{~km}^{2}\right)$.

\begin{tabular}{cccccccc}
\hline $\mathbf{1 9 9 0 / 2 0 0 0}$ & $\begin{array}{c}\text { Arable } \\
\text { Land }\end{array}$ & Forestry & Grassland & $\begin{array}{c}\text { Water } \\
\text { Area }\end{array}$ & $\begin{array}{c}\text { Intertidal } \\
\text { Area }\end{array}$ & $\begin{array}{c}\text { Built-up } \\
\text { Area }\end{array}$ & $\begin{array}{c}\text { Other Unused } \\
\text { Area }\end{array}$ \\
\hline Arable Land & $69,674.45$ & 3.73 & 0.38 & 332.11 & 6.58 & 2278.79 & 0.00 \\
Forestry & 3.24 & 3376.05 & 0.1 & 2.21 & 0.00 & 41.83 & 0.42 \\
Grassland & 109.02 & 0.00 & 1486.16 & 101.5 & 0.00 & 78.85 & 0.00 \\
Water Area & 16.05 & 0.6 & 3.64 & $10,672.69$ & 12.82 & 10.22 & 0.00 \\
Intertidal Area & 0.36 & 0.00 & 0.00 & 30.78 & 2915.46 & 1.52 & 0.00 \\
Built-up Area & 15.68 & 0.00 & 0.32 & 1.02 & 0.00 & $12,263.8$ & 0.00 \\
Other Unused & 0.00 & 0.00 & 0.00 & 1.28 & 0.00 & 0.00 & 19.28 \\
$\quad$ Area & & & & & & \\
\hline
\end{tabular}

Table 4. Land use situation transition matrix in Jiangsu province from 2000 to $2010\left(\mathrm{~km}^{2}\right)$.

\begin{tabular}{|c|c|c|c|c|c|c|c|}
\hline $2000 / 2010$ & $\begin{array}{l}\text { Arable } \\
\text { Land }\end{array}$ & Forestry & Grassland & $\begin{array}{l}\text { Water } \\
\text { Area }\end{array}$ & $\begin{array}{c}\text { Intertidal } \\
\text { Area }\end{array}$ & $\begin{array}{l}\text { Built-up } \\
\text { Area }\end{array}$ & $\begin{array}{c}\text { Other Unused } \\
\text { Area }\end{array}$ \\
\hline Arable Land & $63,342.59$ & 64.77 & 9.35 & 885.36 & 8.12 & 5459.98 & 64.03 \\
\hline Grassland & 121.05 & 1.53 & 815.48 & 283.64 & 79.02 & 125.01 & 64.95 \\
\hline Water Area & 85.57 & 1.2 & 2.52 & $10,792.73$ & 41.6 & 220.45 & 0.64 \\
\hline Intertidal Area & 36.45 & 0.23 & 77.91 & 292.65 & 2486.31 & 39.55 & 0.24 \\
\hline $\begin{array}{c}\text { Other Unused } \\
\text { Area }\end{array}$ & 0.29 & 1.09 & 0.00 & 1.54 & 0.13 & 1.67 & 14.99 \\
\hline
\end{tabular}

\subsection{Land Use Dynamic Degree and Land Use Degree}

The Land Use Dynamic Degree Model and the Land Use Degree Model are reflections of the LUCC evolution process and show the future change trend. We employed the land use dynamic degree model described in Section 2.3 to express the land use dynamic variation, and the change area within the research period (see Table 5).

Table 5. The land use dynamic degree of Jiangsu province from 1990 to 2010.

\begin{tabular}{|c|c|c|c|c|}
\hline \multirow{2}{*}{ Land Use Type } & \multicolumn{2}{|c|}{ From Year 1990 to 2000} & \multicolumn{2}{|c|}{ From Year 2000 to 2010} \\
\hline & Change Area $\left(\mathrm{km}^{2}\right)$ & $\begin{array}{c}\text { Land Use Dynamic } \\
\text { Degree }(\%)\end{array}$ & Change Area $\left(\mathrm{km}^{2}\right)$ & $\begin{array}{c}\text { Land Use Dynamic } \\
\text { Degree (\%) }\end{array}$ \\
\hline Forest & -45.79 & -1.34 & -250.67 & -7.42 \\
\hline Grassland & -284.85 & -16.04 & -554.24 & -37.18 \\
\hline Water area & 428.69 & 4.00 & 1385.07 & 12.43 \\
\hline Other unused area & -0.85 & -4.13 & 196.27 & 995.79 \\
\hline Sum of changes & 5631.19 & 5.44 & $13,942.04$ & 13.47 \\
\hline
\end{tabular}

It was clear to see that from 1990 to 2000, the most obvious land use transition dynamic degree was the built-up area at $19.5 \%$, and it showed a positive trend. Then the grassland was also significant showing $-16.04 \%$ in a negative decreased development direction, whilst for the rest, the land use 
dynamic degree of the water area $(4 \%)$, other unused area $(-4.13 \%)$, and arable land $(-3.41 \%)$ were also obvious. From 2000 to 2010, the other unused areas increased by an amount of $196.27 \mathrm{~km}^{2}$ though it had the most obvious dynamic degree of $995.79 \%$, because the base amount was pretty small at only $19.71 \mathrm{~km}^{2}$. Next was the built-up area of $36.73 \%$, whilst the dynamic degrees of the rest of the land use types were all active. Comparing the land use dynamic degree of two study periods, the built-up area's dynamic degree from 2000 to 2010 was 1.88 times than that from 1990 to 2000. As a whole, the overall land use dynamic degree of Jiangsu province from 2000 to 2010 was 2.48 times much more than that from 1990 to 2000, with a positive development trend. During the 20 year research period, the LUCC in Jiangsu region was active and had a pronounced changing trend.

In order to further the analysis, the land use situation from the human ecology effect was examined, where we employed the land use degree model to describe the index of each land use type within the whole Jiangsu province (Table 6). When the value of the land use degree was above zero, this type of land use was experiencing a developing period, while on the contrary, it was experiencing a recession period. The model results dataset suggested that there was an overall increasing trend of land use degree from 1990 to 2010, as Jiangsu province is located in the Yangtze River Delta developed region that is experiencing an accelerating economic development. Under this rapid development background, the urbanization trend accelerated with urban development, thus, human activity has had a relatively larger effect on the ecology, which is reflected as LUCC.

Table 6. Land use degree of Jiangsu province.

\begin{tabular}{ccc}
\hline Land Use Type & From Year 1990 to 2000 & From Year 2000 to 2010 \\
\hline Arable land & -7.14 & -16.96 \\
Forest & -0.09 & -0.48 \\
Grassland & -0.55 & -1.07 \\
Water area & 0.83 & 2.68 \\
Intertidal area & -0.03 & -0.61 \\
Built-up area & 9.26 & 20.83 \\
Other unused area & 0.00 & 0.19 \\
Sum of total research region & 2.28 & 4.57 \\
\hline
\end{tabular}

The built-up area, water, and other unused areas were experiencing an increasing period at different degrees. It showed that the urban expansion in Jiangsu province was undergoing successful development, as the land use degree of the built-up area was much larger than the others; while the water and other unused areas achieved successful development due to the environmental protection policy of returning arable land back to its natural use. The arable land, forest, grassland, and intertidal areas were all experiencing a recessionary period over these 20 years, reflecting that the high urbanization trend absorbed a large amount of non-built-up land to be changed into urban built-up area. The land use degree of the whole Jiangsu province showed an increasingly active trend, as the land use degree from 2000 to 2010 was more than twice that from 1990 to 2010. This may cause the other unused and intertidal areas to be converted into arable land or changed into grassland and forestry, while the grassland and forestry can be reclaimed into arable land, and the arable land and other types of land changed into built-up areas, etc. Some areas may be different due to local land use policy with different development periods within the whole province.

\subsection{Logistic Regression Analysis}

The logistic regression model was applied to analyze the driving factors of the LUCC. A total of 100,000 random points in Jiangsu province were created using the "Create Random Points" tool in ArcGIS 10.3. We then used the tool "Extract Value to Points" to apply each spatial information to the corresponding random points. To analyze the natural and socio-economic driving factors on the LUCC, we employed the statistical data from the data center, and generated the social related variables based on the newly released point of interest data. We generated the elevation, slope of Jiangsu province, 
GDP, population change, per capita household income, and per capita housing area directly from the statistical data; calculated the distance to the water area, the distance to the highway, distance to the urban road, and distance to the urban center based on the city basic data; and generated the density of commercial service facility, density of transportation facility, and density of other service facility. To confirm the accuracy of the regression result, we used the non-parametric receiver operating characteristic (ROC) curves, and the result showed that all the land use types had a ROC test value that was higher than 0.7 .

The odds ratio (see Table 7) explained the relationship between the variables and the changes of each type of land use. The research result suggested that the thirteen factors forced the LUCC of each type at different directions. Amongst these factors, the elevation only had a relation with the arable land transition, grassland conversion, and the water area loss; the slope affected the location of arable land positively and that of forestry and intertidal area negatively. The distance to water area and the distance to highway affected the changes to all types of natural land, as the water resource is an important consideration in planning site selection. The distance to the urban road affected the grassland positively. The distance to the urban center had a positive effect on the forestry, grassland, and water, while it had a negative effect on built-up area. The density of the transportation facility, the GDP, population change, and per capita housing area all affected the arable land, while the urban construction and economic development consumed a large amount of arable land. These socio-economic related factors all had a positive effect on the built-up area. More details on the driving forces are discussed in Section 4.

Table 7. Odds ratio of the driving forces of each land use type based on the logistic regression analysis.

\begin{tabular}{|c|c|c|c|c|c|c|}
\hline Driving Forces & Arable Land & Forestry & Grassland & Water Area & Built-Up Area & Intertidal Area \\
\hline elevation & 0.889 & - & 1.014 & 0.926 & - & - \\
\hline slope & 1.003 & 0.998 & - & - & - & 0.982 \\
\hline Distance to water area & 1.004 & 0.890 & - & 0.935 & - & 0.999 \\
\hline Distance to highway & 0.916 & 0.788 & - & - & 0.997 & 1.218 \\
\hline Distance to urban road & - & - & 1.014 & - & - & - \\
\hline Distance to urban center & - & 1.012 & 1.000 & 1.000 & 0.892 & - \\
\hline Density of commercial service facility & - & - & - & - & 1.301 & 0.793 \\
\hline Density of transportation facility & 1.012 & - & 1.001 & - & - & 1.001 \\
\hline Density of other service facility & - & 1.012 & - & - & - & - \\
\hline GDP & 0.722 & 0.972 & - & - & 1.163 & - \\
\hline Population change & 0.942 & - & - & - & 1.062 & - \\
\hline Per capita household income & - & 0.927 & - & - & 1.019 & - \\
\hline Per capita housing area & 0.602 & 0.918 & - & - & 1.179 & - \\
\hline
\end{tabular}

\section{Discussion}

The results from the statistical models above showed a detailed analysis of the specific spatio-temporal patterns of LUCC in Jiangsu province over the 20 year rapid development period from 1990 to 2010. The statistical analysis in Section 3.4 described some quantifiable relationships between LUCC and certain driving forces. Natural issues like elevation had a relatively low effect as Jiangsu province is located in the middle and lower regions of the Yangtze River Plain. The construction related reasons may have had more of an effect on the changes to the urban region, as Jiangsu province has experienced a rapid urbanization process over the research period. In general, LUCC was influenced by the natural environment, government policy which is hard to quantify, social economic development, and social technology development. Over the study period, Jiangsu province had a stable economic and social development, where strong economic and population growth were the main driving forces of LUCC within this 20-year small scale time period.

\subsection{Driving Forces of Human Activity}

The land use situation has been influenced by humans through a series of socioeconomic activities over a long-term period [2,57]. Li pointed out that the driving factors of LUCC should be explained by the land use situation change, activity by land users, and the social land use management [2]. As a 
whole, LUCC is a result of the combination of natural and socio-economic change. Human activity related driving forces of LUCC are mainly population increase, urban expansion, urban construction, human migration, and some other government policy issues. Based on Jiangsu province Statistical Yearbook [40], the permanent population of Jiangsu province, the percentage of the population increase, and the percentage of people working for non-agriculture sectors are shown below in Table 8 and Figure 5. It is clear that during this 20-year study period, Jiangsu province had a stable increase in the total permanent population with a linear development trend, and it showed a continued upward trend in the near future. It had a negative effect on the arable land while positively affecting the built-up area expansion. However, a balance should be struck between the conversion of arable land and the built-up area in order to achieve and maintain sustainable development and to reduce the risk to food security as Jiangsu province is an agriculture oriented province in China with a large population $[10,58]$. The percentage of the population working for non-agriculture is continuously increasing at an accelerating rate above the national reported average level, and it suggests a continued trend. The rapid population increase and urbanization situation of the urban area of Jiangsu province have resulted in housing price rises, public transportation congestion, environmental pollution, rising basic living costs, and food security issues, which further accelerate the conversion from arable land to built-up area. Thus, some people have begun to move to sub-urban areas to attain affordable living, such as Jurong which is near Nanjing, Kunshan which is near Shanghai, Pukou New District, etc. This behavior promotes the urbanization process further to the nearby less developed regions, and without a doubt it will continue to accelerate the whole urbanization process of Jiangsu province, whilst having a direct effect on the land use type changes of the built-up area expansion.

Table 8. Population of Jiangsu province.

\begin{tabular}{cccc}
\hline Year & $\begin{array}{c}\text { Permanent Population. } \\
\text { Unit: Ten Thousand }\end{array}$ & $\begin{array}{c}\text { Percentage of } \\
\text { Population Increase }\end{array}$ & $\begin{array}{c}\text { Percentage of } \\
\text { Non-Agriculture Population }\end{array}$ \\
\hline 1990 & 6766.9 & $/$ & $21.56 \%$ \\
1995 & 7066.02 & $4.42 \%$ & $27.30 \%$ \\
2000 & 7327.24 & $3.7 \%$ & $41.50 \%$ \\
2005 & 7588.24 & $3.56 \%$ & $50.50 \%$ \\
2010 & 7869.34 & $3.7 \%$ & $47.88 \%$ \\
\hline
\end{tabular}

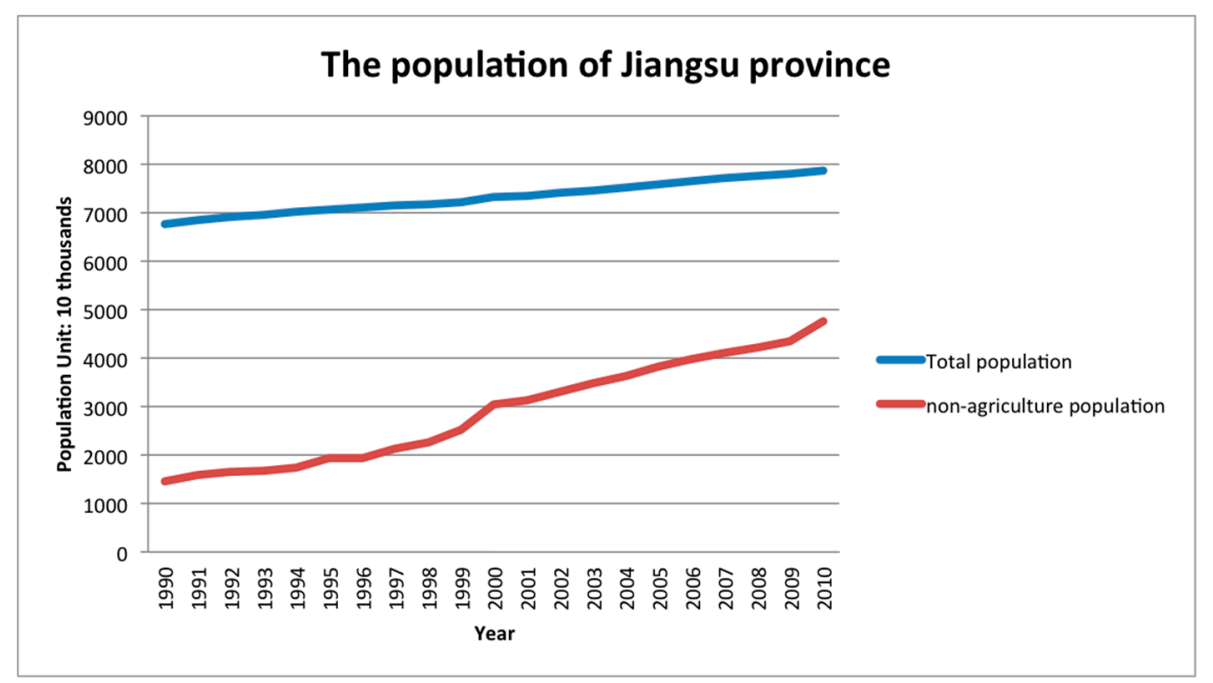

Figure 5. Population changes in Jiangsu province (unit: 10 thousand).

With the remarkable change in people's living standards, residents have begun to seek a better living environment as one of the main driving forces of land use type changes. According to Jiangsu province Statistical Yearbook [40], the per capita housing area was $9.06 \mathrm{~m}^{2}$ per person in 1990, increasing 
to $25.54 \mathrm{~m}^{2}$ per person in 2000, and then continuing to increase to $33.39 \mathrm{~m}^{2}$ per person in 2010. At the same time, the real estate market has developed at an unbelievable pace. While the GDP of the real estate industry was 2.702 billion Chinese yuan (CNY) in 1990, it increased to 29.82 billion CNY in 2000 , and 260.1 billion CNY in 2010. The GDP of the real estate sector developed rapidly with a factor of 96.3 times over the 20-year period. This rising demand for residential areas will lead to the expansion of the built-up area and may occupy more natural land, promoting the transition between arable land, forestry, grassland, or water areas into built-up area to meet the urban expansion demand. Conversely, the government has set up a series of land use protection plans, such as returning forestry to arable land, and thousands of clear farmland projects, with the purpose of protecting the land use red line [59]. This contributes to reducing the land use pressure to a certain degree. During the study period, there was a total of $1295.7 \mathrm{~km}^{2}$ of arable land converted into other types of natural land, which mostly became commercial forest and culture water [60]. These converted areas can not only provide an economic foundation for local farmers, but they also promote environmental protection.

Since the economic reform in 1978, there was significant progress in global communication and technology development. As part of modern societal development, Jiangsu province has built nine airports, and an efficient highway network, which are usually located outside the urban center. Moreover, there have been an increasing number of mega events and international conferences being held in Jiangsu province, which led to the construction of an event center and a nearby hotel, and may cause a certain effect on the land use changes. For example, Nanjing held the Youth Olympic Games in 2014, resulting in a lot of construction programs that occupied a certain amount of arable land in the Hexi district to build an Olympic Village. This kind of activity accelerates the urban infrastructure investment over a short period, increases the public service level, and promotes LUCC without doubt [61].

\subsection{Driving Forces of Socio-Economic Development}

Socio-economic development is usually regarded as one of the most important driving forces of LUCC during the rapid economic growth period. In this research period from 1990 to 2010, Jiangsu province experienced accelerating economic development. The direct reflection is the gross domestic product (GDP) increase, which was 36.87 billion Chinese yuan (CNY) in 1990, and grew to $306.95 \mathrm{CNY}$ in 2000, and continued to increase to 1713.14 CNY in 2010. The total GDP increased by a factor of 46.46 times over the 20-year research period. Additionally, the per capita GDP grew rapidly, where it was 2109 CNY in 1990, increased to 11,765 CNY in 2000, and further increased to 52,840 CNY in 2010. However the growth rate of per capita GDP at a factor of 25 times was less than half that of the total GDP, which was the result of a simultaneous population growth. This overall economic development brought new demand for residential living environments, which may have led to the changes in land use types.

To further study the socio-economic development, the industrial structure also underwent a gradual transformation (Figure 6). We could observe that the industrial structure optimization of the primary industry experienced an accelerating decrease, while the second industry remained slightly stable, and the tertiary industry kept increasing. To be specific, the proportions of the three industries were $25.08 \%, 48.9 \%$, and $26.03 \%$ in 1990 ; changed to $12.26 \%, 51.86 \%$, and $35.89 \%$ in 2000 ; and then optimized into $6.13 \%, 52.51 \%$, and $41.35 \%$ in 2010 . The tertiary industry was directly reflected by the kinds of service facilities in the research area, which were analyzed in Section 3.4 and showed a clear relation with the LUCC. The industrial structure changed faster than the land use dynamic degree. In Jiangsu province, an agriculture oriented province in eastern China, its industrial structure decides the urban function structure change and the corresponding population transition between the agriculture population and non-agriculture population, which was an important pattern during the rapid urbanization process. As one of the significant driving forces behind LUCC, the planning department should pay attention to the inner optimization of the primary industry, limit the expansion of the second industry, and increase the tertiary industry appropriately. 


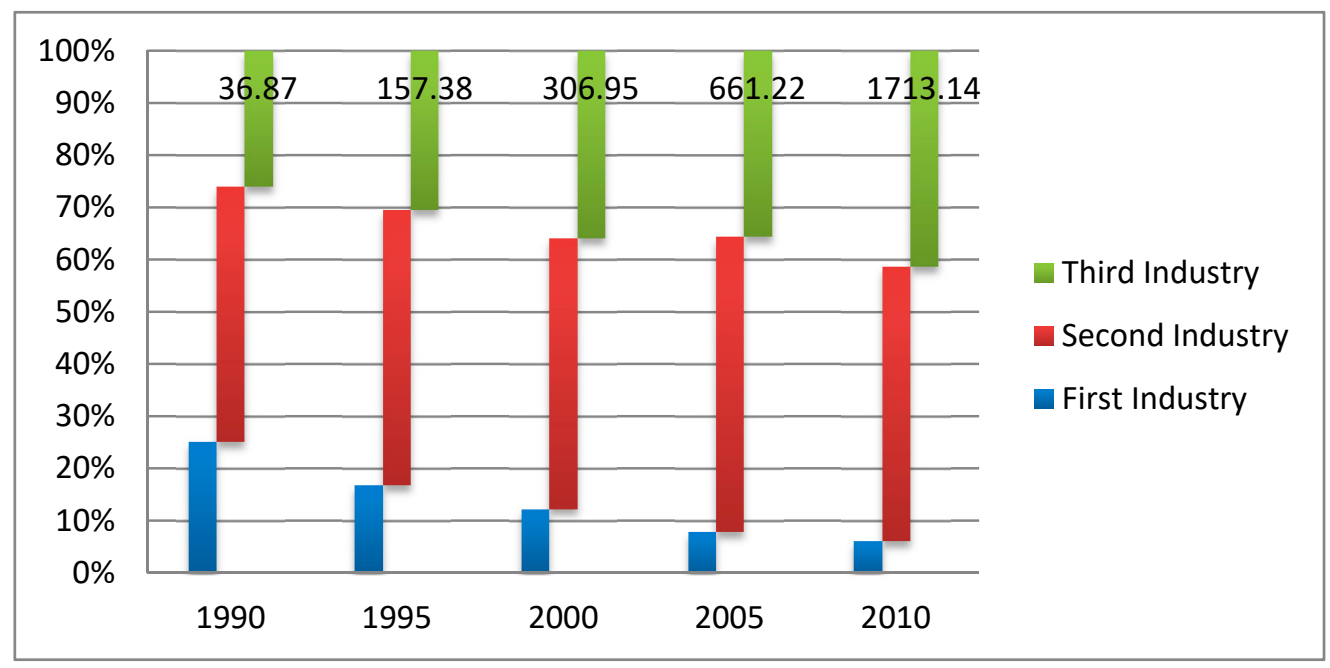

Figure 6. Industrial structure of Jiangsu province expressed by gross domestic product from 1990 to 2010 .

\section{Conclusions}

In this study, we analyzed the spatio-temporal patterns of LUCC over a rapid development period, taking a case study of Jiangsu province from 1990 to 2010. We analyzed the land use type, land use distribution, land use transition matrix between research time periods, land use dynamic degree, land use degree, and the potential driving forces. From the above analysis, the LUCC in Jiangsu can be characterized by three major trends: First is the substantial conversion of agricultural land into non-agricultural land from 1990 to 2010, for example, the rapid expansion of the built-up area, the obvious recession of arable land, and the increase of natural areas for protection purposes. Second, both the land use dynamic degree and land use degree were increasing. Third, the conversion of arable land is a serious issue which deserves more attention to ensure food security, as Jiangsu is an agriculturally-oriented province.

In this research, we used remote sensing technology, the ArcGIS software, new-type POI data, and some statistical methods to analyze the evolution process of the LUCC to obtain an accurate result, and determined the driving forces, as well as providing suggestions for the optimization of future land use planning. In order to achieve a balance between human-land interactions, and to learn more about the future simulation of land use to support decision making in the urban planning of Jiangsu province, the land use dynamic degree, land use degree, and driving factors were proposed to analyze the spatio-temporal evolution of the LUCC at a regional scale. This dynamic change showed a rapid spread of urban construction land, especially around the city centers to the surrounding areas, while the human activities in the urban area had a relatively higher expansion trend. In terms of the land use structure conversion over years, a large amount of arable land was converted into built-up land within this study period. Moreover, there was a significant transition from forestry, grassland, and water areas to built-up areas due to the rapid urban sprawl, as well as the remarkable progress of people's living standards. To boost the sustainable usage of the very limited land resources in developed regions, it is highly necessary for planning departments to seek a win-win method in the dilemma of economic development and arable protection, and to optimize land use planning using various methods, such as adopting satellite towns to replace disorderly central urban expansion. The results found in this study can also be applied to similar regions experiencing rapid economic development. In the future, we should focus more on highly-efficient land use as mega city centers are facing the problem of land use pressure, and we should also pay attention to the sustainable development of land use and global environmental change. 
Author Contributions: G.S. had the original idea, conceived and designed the experiments, analyzed the data, and wrote the paper; P.Y., L.D., and Y.L. did the literature review and analyzed the data; A.G. gave suggestions during the revision period and helped to check the language usage; N.J. reviewed the paper and gave advice on the design of the experiments.

Funding: This research received funding of Postgraduate Research and Practice Innovation Program of Jiangsu Province (KYCX18_1209, KYCX18_1207); National Natural Science Foundation of China (41771421, 41601449; 41501431).

Acknowledgments: We acknowledge the data support from the Yangtze River Delta Science Data Center National Earth System Science Data Sharing Infrastructure, National Science and Technology Infrastructure of China (http:/ / nnu.geodata.cn). We would also like to acknowledge the support provided by the China Scholarship Council, enabling Ge Shi to study at Purdue University supervised by Jie Shan.

Conflicts of Interest: The authors declare no conflict of interest.

\section{Appendix A}
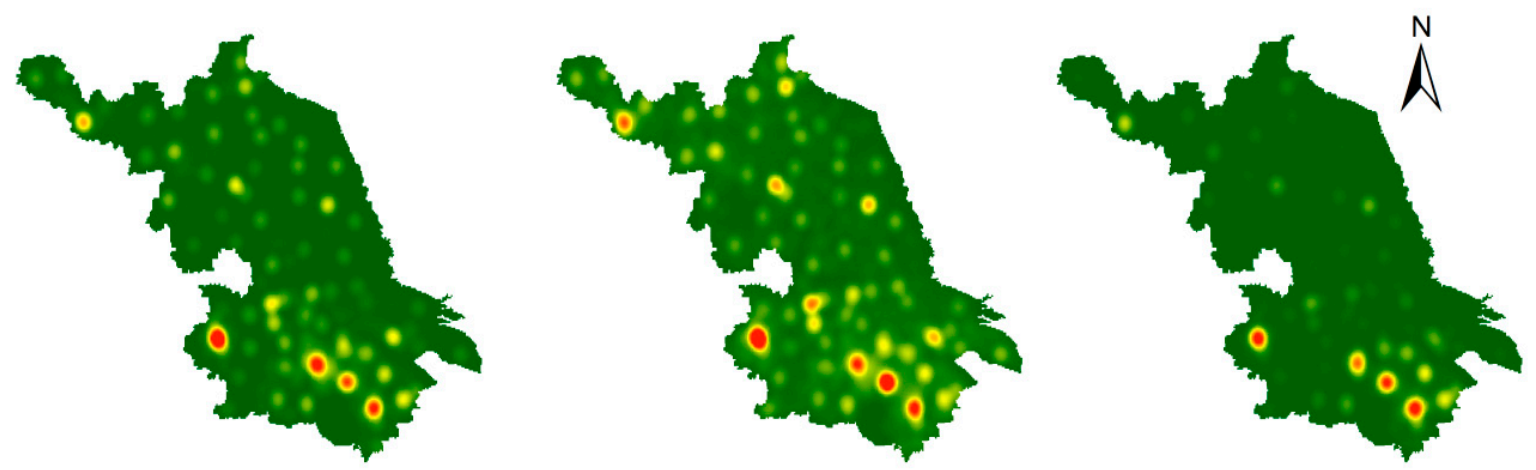

Facility density

Value

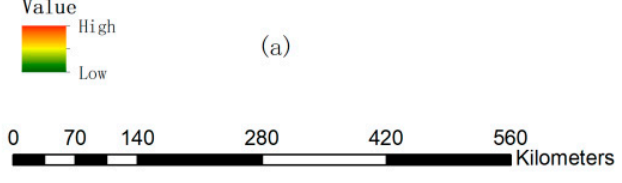

(b)

(c)

Figure A1. Density of service facility: (a) Density of commercial service facility; (b) Density of another service facility; (c) Density of transportation service facility.

\section{References}

1. Lambin, E.F.; Turner, B.L.; Geist, H.J.; Agbola, S.B.; Angelsen, A.; Bruce, J.W.; George, P. The causes of land-use and land-cover change: Moving beyond the myths. Glob. Environ. Chang. 2001, 11, 261-269. [CrossRef]

2. $\mathrm{Li}, \mathrm{X}$. A review of the international researches on land use/land cover change. Acta Geogr. Sin. 1996, 51, 558-565.

3. Shi, G.; Jiang, N.; Yao, L. Land Use and Cover Change during the Rapid Economic Growth Period from 1990 to 2010: A Case Study of Shanghai. Sustainability 2018, 10, 426. [CrossRef]

4. Munroe, D.K.; Müller, D. Issues in spatially explicit statistical land-use/cover change (LUCC) models: Examples from western Honduras and the Central Highlands of Vietnam. Land Use Policy 2007, 24, 521-530. [CrossRef]

5. Liu, J.; Deng, X. Progress of the research methodologies on the temporal and spatial process of LUCC. Chin. Sci. Bull. 2010, 55, 1354-1362. [CrossRef]

6. Hu, Y. An Analysis of Land-Use and Land-Cover Change in the Zhujiang-Xijiang Economic Belt, China, from 1990 to 2017. Appl. Sci. 2018, 8, 1524. [CrossRef]

7. Hao, H.M.; Ren, Z.Y. Land use/land cover change (LUCC) and eco-environment response to LUCC in farming-pastoral zone, China. Agric. Sci. China 2009, 8, 91-97. [CrossRef] 
8. Moran, E.F.; Skole, D.L.; Turner, B.L. The Development of the International Land-Use and Land-Cover Change (LUCC) Research Program and Its Links to NASA's Land-Cover and Land-Use Change (LCLUC) Initiative. In Land Change Science; Springer: Dordrecht, The Netherlands, 2012; pp. 1-15.

9. Skole, D.L.; Justice, C.O.; Townshend, J.R.G.; Janetos, A.C. A land cover change monitoring program: Strategy for an international effort. Mitig. Adapt. Strateg. Glob. Chang. 1997, 2, 157-175. [CrossRef]

10. Yu, W.; Zang, S.; Wu, C.; Liu, W.; Na, X. Analyzing and modeling land use land cover change (LUCC) in the Daqing City, China. Appl. Geogr. 2011, 31, 600-608. [CrossRef]

11. Kummer, D.M.; Turner, B.L. The human causes of deforestation in Southeast Asia. Bioscience 1994, 44, $323-328$. [CrossRef]

12. Sanchez, P.A. Linking climate change research with food security and poverty reduction in the tropics. Agric. Ecosyst. Environ. 2000, 82, 371-383. [CrossRef]

13. Shen, J. Rural development and rural to urban migration in China 1978-1990. Geoforum 1995, 26, 395-409. [CrossRef]

14. Wu, K.Y.; Zhang, H. Land use dynamics, built-up land expansion patterns, and driving forces analysis of the fast-growing Hangzhou metropolitan area, eastern China (1978-2008). Appl. Geogr. 2012, 34, 137-145. [CrossRef]

15. Liu, J.Y.; Liu, M.L.; Deng, X.Z.; Zhuang, D.F.; Zhang, Z.X.; Di, L. The land use and land cover change database and its relative studies in China. J. Geogr. Sci. 2002, 12, 275-282.

16. He, F.; Li, M.; Li, S.; Xiao, R. Comparison of changes in land use and land cover in china and the usa over the past 300 years. J. Geogr. Sci. 2015, 25, 1045-1057. [CrossRef]

17. Li, S.; He, F. Evaluation of global historical land use scenarios based on regional datasets on the Qinghai-Tibet Area. Sci. Total Environ. 2019, 657, 1615-1628. [CrossRef] [PubMed]

18. Gao, Z.Q.; Deng, X.Z. Analysis on spatial features of LUCC based on remote sensing and GIS in China. Chin. Geogr. Sci. 2002, 12, 107-113. [CrossRef]

19. Misselhorn, A.A. What drives food insecurity in southern Africa? A meta-analysis of household economy studies. Glob. Environ. Chang. 2005, 15, 33-43. [CrossRef]

20. Liu, Z.; He, C.; Zhang, Q.; Huang, Q.; Yang, Y. Extracting the dynamics of urban expansion in China using DMSP-OLS nighttime light data from 1992 to 2008. Landsc. Urban Plan. 2012, 106, 62-72. [CrossRef]

21. Shi, G.; Jiang, N.; Li, Y.; He, B. Analysis of the Dynamic Urban Expansion Based on Multi-Sourced Data from 1998 to 2013: A Case Study of Jiangsu Province. Sustainability 2018, 10, 3467. [CrossRef]

22. Long, H.; Qu, Y. Land use transitions and land management: A mutual feedback perspective. Land Use Policy 2018, 74, 111-120. [CrossRef]

23. Wang, C.; Wang, Y.; Wang, R.; Zheng, P. Modeling and evaluating land-use/land-cover change for urban planning and sustainability: A case study of Dongying city, China. J. Clean. Prod. 2018, 172, 1529-1534. [CrossRef]

24. Li, Q.; Yu, Y.; Jiang, X.; Guan, Y. Multifactor-based environmental risk assessment for sustainable land-use planning in Shenzhen, China. Sci. Total Environ. 2019, 657, 1051-1063. [CrossRef] [PubMed]

25. Tang, H.J.; Wu, W.B.; Yang, P.; Chen, Y.Q.; Verburg, P.H. Recent progresses of land use and land cover change (LUCC) models. Acta Geogr. Sin. 2009, 64, 456-468.

26. Puertas, O.L.; Henríquez, C.; Meza, F.J. Assessing spatial dynamics of urban growth using an integrated land use model. Application in Santiago metropolitan area, 2010-2045. Land Use Policy 2014, 38, 415-425. [CrossRef]

27. Saeedi, S. Integrating macro and micro scale approaches in the agent-based modeling of residential dynamics. Int. J. Appl. Earth Obs. Geoinf. 2018, 68, 214-229. [CrossRef]

28. Dan, W.; Wei, H.; Shuwen, Z.; Kun, B.; Bao, X.; Yi, W.; Yue, L. Processes and prediction of land use/land cover changes (LUCC) driven by farm construction: The case of Naoli River Basin in Sanjiang Plain. Environ. Earth Sci. 2015, 73, 4841-4851. [CrossRef]

29. Mooney, H.A.; Duraiappah, A.; Larigauderie, A. Evolution of natural and social science interactions in global change research programs. Proc. Natl. Acad. Sci. USA 2013, 110 (Suppl. 1), 3665-3672. [CrossRef] [PubMed]

30. Ramankutty, N.; Foley, J.A. Estimating historical changes in land cover: North American croplands from 1850 to 1992: GCTE/LUCC RESEARCH ARTICLE. Glob. Ecol. Biogeogr. 1999, 8, 381-396. [CrossRef]

31. Lambin, E.F.; Rounsevell, M.D.A.; Geist, H.J. Are agricultural land-use models able to predict changes in land-use intensity? Agric. Ecosyst. Environ. 2000, 82, 321-331. [CrossRef] 
32. Le, Q.B.; Park, S.J.; Vlek, P.L.; Cremers, A.B. Land-Use Dynamic Simulator (LUDAS): A multi-agent system model for simulating spatio-temporal dynamics of coupled human-landscape system. I. Structure and theoretical specification. Ecol. Inform. 2008, 3, 135-153. [CrossRef]

33. Ralha, C.G.; Abreu, C.G.; Coelho, C.G.; Zaghetto, A.; Macchiavello, B.; Machado, R.B. A multi-agent model system for land-use change simulation. Environ. Model. Softw. 2013, 42, 30-46. [CrossRef]

34. Li, X.Y.; Ma, Y.J.; Xu, H.Y.; Wang, J.H.; Zhang, D.S. Impact of land use and land cover change on environmental degradation in Lake Qinghai watershed, northeast Qinghai-Tibet Plateau. Land Degrad. Dev. 2009, 20, 69-83. [CrossRef]

35. Cheng, Z.; Cao, S. Markov processes in modeling land use and land cover change in Tibetan Plateau. In Proceedings of the 2011 International Conference on Remote Sensing, Environment and Transportation Engineering (RSETE), Nanjing, China, 24-26 June 2011; pp. 457-459.

36. Zhang, B.; Mao, Y.C.; Liu, J.F. Analysis driving forces of LUCC in Heihe middle reaches. Arid Land Geogr. 2006, 29, 726-730.

37. Liu, J.; Zhang, Z.; Xu, X.; Kuang, W.; Zhou, W.; Zhang, S.; Jiang, N. Spatial patterns and driving forces of land use change in China in the early 21st century. Acta Geogr. Sin. 2009, 12, 1411-1420. [CrossRef]

38. Du, X.; Jin, X.; Yang, X.; Yang, X.; Zhou, Y. Spatial pattern of land use change and its driving force in Jiangsu Province. Int. J. Environ. Res. Public Health 2014, 11, 3215-3232. [CrossRef] [PubMed]

39. National Bureau of Statistics of the People's Republic of China. China Statistical Bureau 2017. Available online: http:/ / www.stats.gov.cn (accessed on 14 June 2018).

40. National Bureau of Statistics of the People's Republic of China. Jiangsu Statistical Yearbook 2016. Available online: http:/ / www.jssb.gov.cn/2016nj/nj03.htm (accessed on 14 June 2018).

41. The Department of Land Resource of Jiangsu Province. The Comprehensive Land Use Planning of Jiangsu Province. Available online: http://www.jsmlr.gov.cn/gtxxgk/nrgllndex.action?type=2\&messageID= 8a90825440beba390140c2b9d93a6ec9 (accessed on 14 June 2018).

42. Pielke, R.A. Land use and climate change. Science 2005, 310, 1625-1626. [CrossRef] [PubMed]

43. Kalnay, E.; Cai, M. Impact of urbanization and land-use change on climate. Nature 2003, 423, 528. [CrossRef] [PubMed]

44. Cheng, J.I.N.; Yuqi, L.U. Evolvement of Spatial Pattern of Economy in Jiangsu Province at County Level. Acta Geogr. Sin. 2009, 6, 10.

45. Yangtze River Delta Science Data Center, National Science and Technology Infrastructure of China. National Earth System Science Data Sharing Infrastructure. 2015. Available online: http:/ /nnu.www.geodata.cn:8008 (accessed on 10 August 2018).

46. Bureau of Statistics of Jiangsu Province. Jiangsu Yearbook. Available online: http://tj.jiangsu.gov.cn/col/ col4009/index.html (accessed on 2 August 2018).

47. Bell, E.J. Markov analysis of land use change-An application of stochastic processes to remotely sensed data. Socio-Econ. Plan. Sci. 1974, 8, 311-316. [CrossRef]

48. Zheng, J.K.; Yu, X.X.; Jia, G.D.; Xia, B. Dynamic evolution of the ecological service value based on lucc in miyun reservoir catchment. Trans. Chin. Soc. Agric. Eng. 2010, 26, 315-320.

49. Wang, X.L.; Bao, Y.H. Study on the methods of land use dynamic change research. Prog. Geogr. 1999, 18, 81-87.

50. Wang, S.Y.; Liu, J.Y.; Zhang, Z.X.; Zhou, Q.B.; Zhao, X.L. Analysis on spatial-temporal features of land use in China. Acta Geogr. Sin. 2001, 56, 639-647.

51. Liu, J.; Liu, M.; Zhuang, D.; Zhang, Z.; Deng, X. Study on spatial pattern of land-use change in China during 1995-2000. Sci. China Ser. D Earth Sci. 2003, 46, 373-384.

52. Zhuang, D.; Liu, J. Study on the model of regional differentiation of land use degree in China. Chin. Geogr. Sci. 1997, 7, 302-309. [CrossRef]

53. Zhao, G.; Liu, J.; Kuang, W.; Ouyang, Z.; Xie, Z. Disturbance impacts of land use change on biodiversity conservation priority areas across China: 1990-2010. J. Geogr. Sci. 2015, 25, 515-529. [CrossRef]

54. Millington, J.D.A.; Perry, G.L.W.; Romero-Calcerrada, R. Regression techniques for examining land use/cover change: A case study of a mediterranean landscape. Ecosystems 2007, 10, 562-578. [CrossRef]

55. Brant, R. Assessing proportionality in the proportional odds model for ordinal logistic regression. Biometrics 1990, 46, 1171-1178. [CrossRef]

56. Turner, B.L. Local faces, global flows: The role of land use and land cover in global environmental change. Land Degrad. Dev. 1994, 5, 71-78. [CrossRef] 
57. Zhang, J.; Li, J.; Chen, Y.; Yang, Q.; Gang, C.; Odeh, I.O.; Zou, X. Comparative Study on LUCC and CLID of Zhangiiagang, Hanoi and Dehradun in the developing countries of Asia-Pacific region: A real challenge to food security. In Proceedings of the 2011 International Conference on Remote Sensing, Environment and Transportation Engineering, Nanjing, China, 24-26 June 2011.

58. Godfray, H.C.J.; Beddington, J.R.; Crute, I.R.; Haddad, L.; Lawrence, D.; Muir, J.F.; Toulmin, C. Food security: The challenge of feeding 9 billion people. Science 2010, 327, 812-818. [CrossRef]

59. Yan, H.M.; Liu, J.Y.; Huang, H.Q.; Dong, J.W.; Xu, X.L.; Wang, J.B. Impacts of Cropland Transformation on Agricultural Production under Urbanization and Grain for Green Project in China. Acta Geogr. Sin. 2012, 5, 579-588.

60. Ye, J. Land transfer and the pursuit of agricultural modernization in china. J. Agrar. Chang. 2015, 15, 314-337. [CrossRef]

61. Lee, C.K.; Taylor, T. Critical reflections on the economic impact assessment of a mega-event: The case of 2002 FIFA World Cup. Tour. Manag. 2005, 26, 595-603. [CrossRef]

(C) 2019 by the authors. Licensee MDPI, Basel, Switzerland. This article is an open access article distributed under the terms and conditions of the Creative Commons Attribution (CC BY) license (http:/ / creativecommons.org/licenses/by/4.0/). 